\title{
The Effect of a G roup Counseling Program Based on a Cognitive - Behavioral Therapy on the Treatment of Type A Behavior
}

\author{
Bakkar S. Bakkar* \\ Sultan Qaboos University, Oman
}

\author{
Mohammad T. A buel-Ealeh \\ Sultan Qaboos University, Oman
}

The purpose of this study was to examine the effect of a group counseling program based on cognitive - behavioral therapy on reducing the Type A behavior pattern. The study attempted to test the following hypothesis: participants who receive group counseling based on cognitive - behavioral therapy will report significant reduction in the Type $A$ behavior pattern compared to participants in the control group who don't receive any kind of treatment. A Type A Behavior Scale (TABS) was constructed to assess the extent to which the subjects have Type $A$ behavior. The sample consisted of 24 students selected based on their TABS scores (above the mean). These subjects were randomly assigned into two groups: Experimental group ( $n=12$ students) who received group counseling based on cognitive - behavioral therapy, and a control group ( $n=12$ students) who didn't receive any treatment. Means, standard deviations, and Analysis of covariance revealed that there were significant differences between the experimental group and the control group in the reduction of Type A behavior. This significant reduction was greatly in favor of the experimental group subjects.

Keywords: Type A behavior, group counseling program, and cognitive- behavioral therapy.

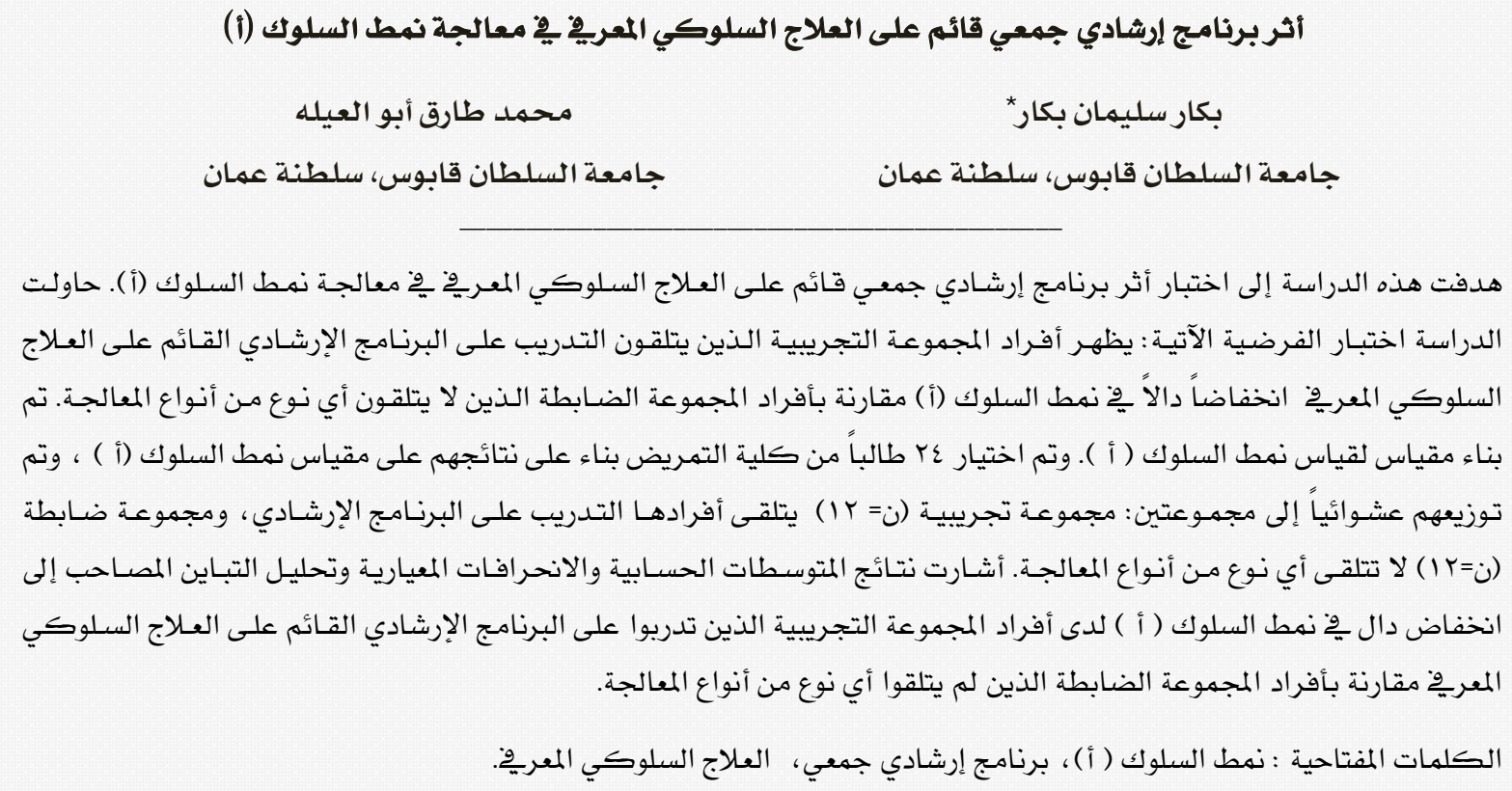

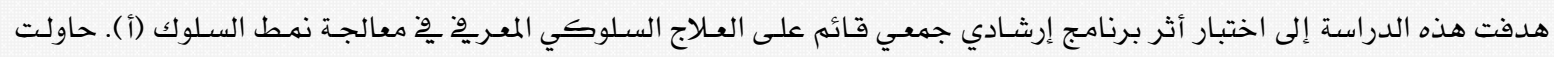

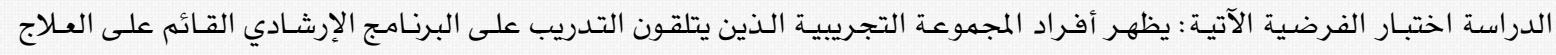

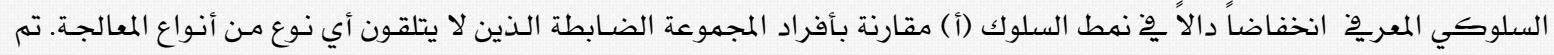
بناء مقياس لقياس نمط السلوك ( أ ). وتم اختيار عr طالباً من كلية التمريض بناء على نتائجهم على مقياس نمط السلوك (أ ) ، وتم

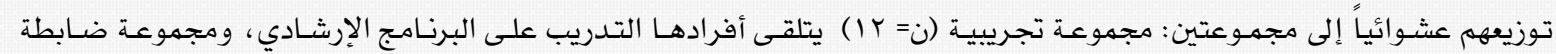

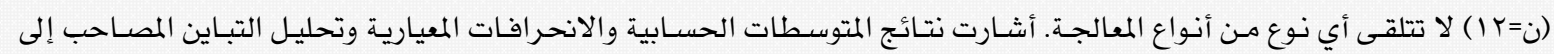

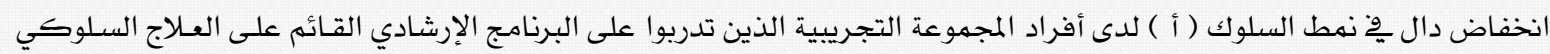
المعروِّمقارنة بأفراد المجموعة الضابطة الذين لم يتلقوا أي نوع من أنواع المعالجة.

$$
\text { الكلمات المفتاحية : نمط السلوك ( أ)، برنامج إرشادي جمعي، العلاج السلوكي المعرِّ. }
$$

*bakkar@squ.edu.om 
Type A behavior pattern is one of basic personality types that needs in-depth research, because it is strongly related to health. This type is always studied under stress, so it is considered as one of risky problems in this time. It is also killing and lethal; because it causes heart attack resulting from coronary heart disease (CHD).

Coronary heart disease (CHD) is one of the pathologies that have been studied the most in relation to personality and psycho-emotive stress. The etiological and prognostic independent link between stress (acute or chronic) and various clinical cardiovascular outcomes, including the onset of CHD, infarction (lethal and non-lethal) and coronary artery disease (CAD), which can be divided into different categories of seriousness, is recognized both in the medical and psychological spheres ( $\mathrm{He}$ mingway, 1999, Strike, and Steptoe, 2004).

Further evidence of the relationship between stress and coronary heart disease was presented in the studies of Meyer Friedman and Ray Rosenman. Friedman and Rosenman, the two cardiologists, were the first to coin and define the Type A behavior pattern. They later compared patients with coronary heart disease with healthy controls (people similar in all respects except they did not have coronary heart disease) and found a significantly greater degree of Type A behavior in the patients than in the controls (Greenberg, 2008). The Type A behavior pattern, particularly hostility, in addition to high life stress and poor social networks, increases the risk for acute cardiovascular events and long-term coronary artery disease (Lehrer, Woolfolk \& Sime, 2007).

In 1959, Friedman and Rosenman identified the characteristics of Type A Behavior Pattern in six behaviors: (1) An intense and continuing drive to attain personal goals which were frequently poorly defined, (2) extreme competitiveness, (3) persistent need for recognition and advancement, (4) accelerated rate of physical and mental functioning, (5) mental and physical alertness, and (6) continuous involvement in activities subject to time limits. In 1974, Friedman and Rosenman revised their definition to emphasize extreme aggressiveness, hostility, time-urgency, and competitive achievement striving. They ultimately described Type A individuals as "aggressively involved in a chronic, incessant struggle to achieve more and more in less and less time, and if required to do so, against the opposing efforts of other things or other persons" (Friedman \& Rosenman, 1974, p. 67).

Friedman \& Rosenman (1974) pointed out that an environmental challenge serves as a fuse that ignites Type $A$ behavior patterns and causes an explosion. It is the interaction of specific personality characteristics and an environmental challenge, usually a stressor of some sort, that results in the Type A pattern.

The complement to the Type A pattern is the Type B pattern, characterized by a less hurried, less competitive existence. Type B individuals are equally intelligent and may be just as ambitious as those who are Type A, but they approach their life in a more measured way. Even when blood pressure, smoking, cholesterol and other known risk factors are taken into consideration, Type A individuals have 1.5-2 times the risk of heart attack in comparison with Type B individuals (Quick, Quick, Nelson \& Hurrell, 1997).

The characteristics of the TABP are: impatience, aggression, an intense motivation to reach their objectives which become ever greater, a sense of urgency with regard to time and a desire to make progress and be recognized. The counterpart of the TABP is the type $B$ pattern, characterized by patience and tranquility, a moderated sense of urgency with regard to time and little aggression or competition (Compare, Manzoni, and Molinari, 2006).

The TABP, generally characterized by extremes of competitive striving for achievement, impatience, hostility, aggressiveness and an exaggerated sense of time urgency, has been associated with academic performance, work performance, job attitudes, escalation of commitment, short-term health outcomes, and increased risk for traffic accidents (Moller, 2006).

Swan and Carmelli (1988) summarized individuals with TABP in terms of: 1 ) intense, sustained drive to achieve self-selected but often poorly defined goals; 2) profound eagerness to compete and need to "win"; 3) persistent desire for recognition and advancement; 4) continuous involvement in multiple and diverse activities under time constraints; 5) habitual tendency to increase the rate of doing 
most physical and mental activities; 6) extreme mental and physical alertness; and 7) pervasive aggressive and hostile feelings.

Type A behavior pattern is defined as :a particular complex of personality traits, including excessive competitive drive, aggressiveness, impatience, and a harrying sense of time urgency, as well as a free-floating but wellrationalized form of hostility, and almost always a deep-seated insecurity. This behavior pattern has been found to be associated with the development of coronary heart disease (Greenberg, 2008, pg. 115), and linked to a myriad of stress related illnesses and problems (Begley, Lee, \& Czajka, 2000).

Pedersen and Denolle (2003) pointed out that the TABP was purposely defined to avoid any association with personality traits, even though in practice it ended up adhering to the dominant "mecanomorphic" paradigm, and was even referred to as "Type A personality." They also affirmed that the TABP was not conceived as a stable personality profile.

Data obtained from cases of acute infarction suggests that psychosocial factors-such as anxiety, depression, hostility, Type A behavior, social supports, and work characteristics-show consistent, independent, doseresponse relations with coronary heart disease. Evidence from prospective epidemiological studies also suggests that psychosocial factors-such as anxiety, depression, hostility, Type A behavior, social supports, and work characteristics-may play a direct causal role in coronary heart disease ( Williams, 2002).

An initial goal in cognitive behavior therapy (CBT) is to help a patient restructure his thinking by first becoming more aware of his thought processes. The therapist stresses that learning to catch one's thoughts is a necessary step in correcting distortions. The patient frequently finds that increasing self-awareness is sufficient to start correcting his thinking errors. Self-awareness allows him/ her to distance himself/ herself from faulty thinking and develop a more objective perspective toward a situation. As the patient begins to collect automatic thoughts, the therapist gains a greater understanding of the patient's vulnerability and of the specific schemas that control his perception of feared situation (Beck and Emery, 1985).
CBT has shown impressive efficacy in treating individuals with anxiety disorders and has often been considered a first-line treatment for anxiety. Most of the CBT approaches for treatment of anxiety can be divided into: 1 . Exposure therapy and 2. Anxiety management. Many CBT treatments include some form of exposure therapy, which is recommended for most, if not all, the anxiety disorders. Exposure therapy has its basis in the animal studies literature on extinction training. During extinction training, the feared stimuli are presented repeatedly with no aversive consequences; the fear decreases until, ideally, the stimuli no longer engender fear. The other major CBT approach to treating anxiety is anxiety management training (AMT). Exposure helps address excessive avoidance, whereas AMT helps address excessive arousal. The two most popular components of AMT are cognitive restructuring and relaxation. In cognitive restructuring, the patient's cognitive errors are made explicit, and means of correcting these errors are taught. Relaxation techniques often include breathing retraining and/ or deep muscle relaxation (Gerardi, Ressler \& Rothbaum, 2009).

Cognitive Behavior Therapy (CBT) operates under the premise that individuals possess disruptive, dysfunctional/ irrational cognitions about events that negatively impact their behavior and affect. That is, cognitions mediate emotions and behaviors. This is different from a cognitive deficit model, which implies that typical normal development involves the acquisition of certain cognitive processes that have failed to develop in these children who experience difficulty (Terjesen, \& Esposito, 2006).

According to Ellis (1997), Rational-Emotive Behavior Therapy (REBT) and Cognitive Behavior Therapy (CBT) lend themselves particularly well to use in group settings. Ellis (2002) stated: "Rational-Emotive Behavior Therapy (REBT) and Cognitive-Behavior Therapy (CBT) are efficient kinds of group therapy, because they involve people who regularly meet together with a leader in order to work on their psychological problems, they focus on the members' thoughts, feelings and behaviors, and they encourage all the participants to help each other change their cognitions, emotions and actions" (p. 51). 
Cognitive - behavioral therapy techniques are part of Rational Emotive Behavioral Therapy (REBT) of Ellis, and Cognitive Therapy (CT) of Beck. These techniques are diverse and suitable to different clients, so they may be applied to different situations and disorders. According to the literature, they were included in different counseling and therapeutic programs. Cognitive - behavioral techniques help to implement cognitive restructuring strategy that is the basic strategy of reshaping the client's thinking. This strategy is considered as an integrative approach in cognitive - behavioral therapy. The therapeutic techniques of (REBT) and (CT) can be summarized as follows:

Disputing irrational beliefs: The most common cognitive method of REBT consists of the therapist actively disputing clients' irrational beliefs and teaching them how to do this challenging on their own. Clients go over a particular "must," "should," or "ought" until they no longer hold that irrational belief, or at least until it is diminished in strength. Here are some examples of questions or statements clients learn to tell themselves: "Why must people treat me fairly?" "How do I become a total flop if I don't succeed at important tasks I try?" "If I don't get the job I want, it may be disappointing, but I can certainly stand it." "If life doesn't always go the way I would like it to, it isn't awful, just inconvenient." (Corey, 2104).

Doing cognitive homework: REBT clients are expected to make lists of their problems, look for their absolutist beliefs, and dispute these beliefs. They often fill out the REBT Self-Help Form, and bring it to their therapy sessions and critically evaluate the disputation of some of their beliefs. Homework assignments are a way of tracking down the absolutist "shoulds" and "musts" that are part of their internalized self - messages. Part of this homework consists of applying the A-B-C model to many of the problems clients encounter in daily life. Work in the therapy session can be designed in such a way that out-of-office tasks are feasible and the client has the skills to complete these tasks (Corey, 2104).

Role playing: Role playing has emotive, cognitive, and behavioral components, and the therapist often interrupts to show clients what they are telling themselves to create their disturbances and what they can do to change their unhealthy feelings to healthy ones. Clients can rehearse certain behaviors to bring out what they feel in a situation. The focus is on working through the underlying irrational beliefs that are related to unpleasant feelings (Corey, 2104).

U se of force and vigor: Ellis has suggested the use of force and energy as a way to help clients go from intellectual to emotional insight. Clients are also shown how to conduct forceful dialogues with themselves in which they express their unsubstantiated beliefs and then powerfully dispute them. Sometimes the therapist will engage in reverse role playing by strongly clinging to the client's selfdefeating philosophy. Then, the client is asked to vigorously debate with the therapist in an attempt to persuade him or her to give up these dysfunctional ideas. Force and energy are a basic part of shame-attacking exercises (Corey, 2104).

Behavioral techniques: REBT practitioners use most of the standard behavior therapy procedures, especially operant conditioning, self-management principles, systematic desensitization, relaxation techniques, and modeling. Behavioral homework assignments to be carried out in real-life situations are particularly important. These assignments are done systematically and are recorded and analyzed on a form. Homework gives clients opportunities to practice new skills outside of the therapy session, which may be even more valuable for clients than work done during the therapy hour (Ledley, Marx, \& Heimberg, 2005).

Relaxation training: This technique has become increasingly popular as a method of teaching people to cope with the stresses produced by daily living. It is aimed at achieving muscle and mental relaxation and is easily learned. After clients learn the basics of relaxation procedures, it is essential that they practice these exercises daily to obtain maximum results. Relaxation training involves several components that typically require from 4 to 8 hours of instruction. Clients are given a set of instructions that teaches them to relax. They assume a passive and relaxed position in a quiet environment while alternately contracting and relaxing muscles. This progressive muscle relaxation is explicitly taught to the client by the therapist. Deep and regular 
breathing is also associated with producing relaxation (Corey, 2014).

Beck and Weishaar (2008) described both cognitive and behavioral techniques that are part of the overall strategies used by cognitive therapists. Techniques are aimed mainly at correcting errors in information processing and modifying core beliefs that result in faulty conclusions. Cognitive techniques focus on identifying and examining a client's beliefs, exploring the origins of these beliefs, and modifying them if the client cannot support these beliefs. Examples of behavioral techniques typically used by cognitive therapists include skills training, role playing, behavioral rehearsal, and exposure therapy. Regardless of the nature of the specific problem, the cognitive therapist is mainly interested in applying procedures that will assist individuals in making alternative interpretations of events in their daily living.

A cognitive-behavioral approach to treating the Type A behavior pattern targets selfcriticizing thoughts. This approach attempts to replace dysfunctional beliefs with new beliefs. One of these new beliefs is that the things one strives for are as important as the things one wishes for. A nother new belief is the notion that no matter how many things one accumulates, this cannot compensatefor the emotional deprivation experienced in childhood. Consequently, cognitive-behavioral interventions focus on the appraisal processes and belief systems of Type A individuals to reduce Type A responses (Sorensen, 2006).

More generally, however, the effects of the cognitive - behavioral therapy on the treatment of Type A behavior were investigated and well documented in different research settings related to this area, but the number of these studies is not considerable. Sorensen (2006) examined the effectiveness of treating the Type A behavior pattern using cognitivebehavioral therapy in comparison to other theoretical orientations. The cognitivebehavioral group which included 31 Type A individuals was found to have significantly higher improvement ratings during the course of treatment than did the group consisting of other theoretical orientations.

Army Physical Fitness Research Institute conducted a study to examine the effect of a TYPE "A" Behavior Modification program. The subjects were the US Army War College (AWC) resident students, whose age ranged from 40 to 50. All of these students have been diagnosed as exhibiting excessive TYPE "A" behavior, which may contribute to future coronary disease. Two hour cognitive -behavior modification group therapy sessions with 8-14 of the most needy Type "A" students were conducted. The findings indicated that the program was effective in modifying the Type A behavior (Federal Information \& News Dispatch, 2001).

George, Prasadarao, Kumaraiah, \& Yavagal (1998) attempted to find out the effectiveness of a cognitive behavioral intervention program in: a. modifying Type A Behavior Pattern (TABP), b. reducing anxiety and c. changing maladaptive assumptions in a subject who had CHD. A single case design (a 55 year old married, male, doctor) with pre mid- and posttreatment assessments was used. The Cognitive behavioral intervention program developed based on the assessment and functional analysis consisted of: Coronary Counseling, education about TABP, Stress Inoculation Training (SIT) and behavioral counseling to significant others. Findings indicated the significant effectiveness of such intervention program in the modification of TABP and associated problems (e.g. anger, anxiety, Central Serous Retinopathy (CSR), dysfunctional cognitions, etc.).

Möller and Botha (1996) investigated the outcome of cognitive restructuring based on Rational-Emotive Behavior Therapy (REBT) in a group of 44 healthy male Type $A$ insurance representatives after 15 hours of group treatment. Results showed significant reductions in intensity of Type A behavior and the time urgency component from pre to post treatment, which were maintained at follow-up after 10 weeks.

Burell, Ohman, Sundin ,Strom, Ramund, Culhed and Thoresen (1994) conducted a study to examine the effects of Type A modification on a sample of 49 male post - myocardial infraction patients who were recruited from the section of cardiology, department of internal medicine, Uppsala University hospital, Sweden. This modification consisted of cognitive behavioral techniques, such as: cognitive restructuring, role playing, modeling, and relaxation. Subjects were randomly assigned into two groups: experimental which received the cognitive - behavioral treatment, 
and control group which didn't receive any treatment. Findings revealed that there were significant reductions of Type A behavior in experimental group patients.

Bennett, Wallace, Carroll, and Smith (1991) compared cognitive behavioral treatment with stress management and delayed treatment in mild hypertensives. The cognitive-behavioral condition resulted in reduced TABP at posttreatment after 8 weeks and at 6-month follow-up. These changes were associated with physiological changes (e.g., reduced systolic blood pressure).

\section{Statement of the Problem}

Therapeutic interventions were compared to determine if a certain technique is more effective in working with individuals characterized by Type A behavior than are other techniques. Not only is this information important in therapy sessions with clients who behave this way, it is also valuable in conceptualizing the people who are especially susceptible to coronary heart disease. Specifically, the researcher compared the difference in the outcome of treating the Type A behavior pattern using cognitive-behavioral techniques. It was hypothesized that using these techniques to treat individuals with Type A would lead to better outcomes. This study attempted to answer the following questions: what is the effect of a group counseling program based on cognitive-behavioral therapy on reducing the Type A behavior pattern? To answer this question; the following hypothesis was formulated:

"Individuals of the experimental group who receive the group counseling program based on cognitive - behavioral therapy will report significant reduction in the Type $A$ behavior pattern when compared to the individuals of control group who don't receive any kind of treatment".

\section{Rationale}

Some university and college students experience different stresses in their life. Theses stresses result from diverse stressful events related to academic, social, economic and emotional aspects. Some persons may develop certain type of personality as a result of accumulation of these events. In this case, stress will become chronic, if help or treatment is not provided. The chronic stress contribute to the development of Type A behavior pattern which is considered as a risk factor of coronary artery disease (CAD). There is plenty of evidence that chronic stress is often a companion of college students. As they observed college students, researchers Towbes and Cohen (1996) concluded that college students are particularly prone to chronic stress as a result of their experiencing and having to manage developmental transitions. The stress experienced by college students can interfere with the learning processes (acquisition, manipulation, and consolidation of knowledge) necessary for academic success. Having difficulties academically then feeds back into the stress loop as a life-situation stressor to create even more stress. Other stress researchers have noted students' concerns such as finances, living arrangements, safety, and their weight to be significant stressors (Greenberg, 2008). Consequently, there is an urgent need to reduce chronic stress by eliminating stressful events in the academic life, and conduct therapeutic and counseling programs to treat this behavior in college students.

The literature on the TABP revealed that relatively little has been written on how to conceptualize this behavior pattern, thereby emphasizing the need for a comprehensive theoretical model of TABP. Such a model would not only provide a framework for integrating existing empirical data, it would also allow for more appropriate treatment to be developed. The few early intervention studies yielded either mixed results or provided moderate support for changing the TABP .However; these studies were criticized for their small sample sizes and for using self-report measures in assessing TABP.

There have been several reviews of TABP outcome studies. In general, these reviews showed that, despite methodological shortcomings in some studies, reductions of TABP are associated with positive psychosocial or cardiovascular outcomes. The results of TABP intervention studies, although limited in number and despite conceptual and methodological shortcomings, are highly encouraging. They showed that TABP can be altered, and that reduced TABP is related to improved physical and psychosocial health status.

The importance of this study emerges from the objectives of our counseling program which were to: a. Develop insight into and create 
self-awareness of the manifestation and consequences of TABP. b. Teach strategies for physical and psychological relaxation. Provide behavioral exercises for developing healthier Type B behaviors, particularly with respect to hostility and time urgency. d. Help participants recognize and modify Type $A$ attitudes and beliefs, particularly regarding insecurity and negative self-esteem. e. Help them improve interpersonal relationships, and. f. Assist participants in developing a healthier philosophy of living.

The rate and process of change vary considerably among participants. Some individuals improve rapidly, others require repeated and intensive work and time to change their Type A behaviors, while others make no progress at all, due to their profound fear of relinquishing control and their inability to tolerate the anxiety inherent in change (Bracke \& Thoresen, 1996).

\section{O perational definition}

The Type A behavior is operationally defined as a state of stress, in which a set of insisting demands instigate the individual to meet them; consequently, he mobilizes himself to achieve more and more in less and less time, and the individual manifests tremens, diaphoresis, hypothermia and electric charges in his hands, he also manifests tachycardia, hyperpnoea, and he couldn't breathe regularly, his face tends to be pale whatever he eats, his weight will still be low, he on the one hand, represses his emotions at the expense of his heart and health, but on the other hand, he tends to make catharsis, aggression, and he has a rapid movements in his limbs. It is divided into four domains: (A) Urgency, Irritability - impatience, (B) Energy - Ambition, competitiveness, (C) Hostility-aggressiveness, (D) physiological signs, somatic symptoms.

\section{A. Urgency, Irritability - and Impatience:}

- Urgency is operationally defined as individual's insisting on achieving more and more demands in less and less time or his insisting on achieving the demand, although it is not important. In addition, the individual may insist on doing the task hastily.

- Irritability is operationally defined as the level of anxiety and stress without feeling relaxed as a results of not achieving the demand.
- Impatience is the individual's inability to wait to do the task in time.

B. Energy - A mbition, competitiveness.

- Energy is stated as individual's potential to work and to do the demand; the re quired fuel to achieve the demands or targets of ambition; energy level reflects the ambition level of the individual.

- Ambition reflects what the individual intends to do or achieve in the future; that's, he/ she aspires to reach the level of culmination.

- Competitiveness: is an important motive to superiority, and discrimination, it needs potentials and persistence, which create a climate to work hard without any hostility.

C- Hostility and aggressiveness are making verbal or corporal punishment against self or others, in addition, it also involves vandalism (destruction of his domains or people's domains).

D- Physiological signs and somatic symptoms and signs resulting from changing in chemical and physical quantities in some organs of the body such as: heart, lungs, stomach, intestines, skin and mouth, these changes may include hypertension, peptic ulcer, loss of appetite, pruritus, diaphoresis, decreasing of saliva secretion, face color and movement, limbs movement, hyperthermia, hyperpnoea...etc.

\section{METHOD}

\section{Participants}

The participants recruited to this study were 97 male students in Nursing college at Sultan Qaboos University ; because males are thought to be more likely to cooperate with the program, whereas females are more reluctant to participate due to cultural factors. The TABS was administered to them to identify the students who have Type A behavior pattern. The sample consisted of 24 students selected based on their TABS scores (above the mean). These subjects were randomly assigned into two groups: Experimental group $(n=12)$ whose individuals received the group-counseling program based on cognitive - behavioral therapy, and control group $(n=12)$ whose individuals didn't receive any treatment. 


\section{Measure}

A Type A Behavior Scale (TABS) was constructed by authors to assess the extent to which do the subjects have Type A behavior. The construction process was based on indepth review of the literature related to Type A behavior and its dimensions. The TABS in its primary version was composed of 90 items which measure Type A behavior in the following dimensions: (A) Urgency, irritability - impatience (34) items. (B)Energy - ambition, competitiveness (23) items, (C) Hostility- aggressiveness (14) items (D) physiological signs, somatic symptoms (19) items. After estimating the validity of the (TABS); the final version consisted of 78 items distributed as follows: Urgency, irritability - impatience (30) items. (B)Energy - ambition, competitiveness (20) items, (C) Hostility- aggressiveness (12) items (D) physiological signs, somatic symptoms (16) items. The TABS items were calculated by rating the degree of having the Type $A$ behavior according to a five - point scale: (extremely $=5$, very $=4$, moderately $=3$, slightly $=2$ and not at all $=1$ ). The total score (maximum score) obtained by summing up the scores of all items was 390, the minimum score was 78, and the average score was 234.

\section{Validity}

Content validity was assessed based on program goals. The TABS was submitted to a panel of experts who have a PhD in counseling, nursing and psychiatry. They were asked to indicate the extent to which every item is highly adequate or inadequate. If an item was inadequate, they were asked to delete or modify it. The experts were provided with an operational definition for every dimension in order to simplify the assessment of the TABS validity. The Original version of the TABS consisted of 90 items. Most of these items (71 items) were found to be highly adequate, but some items ( 7 items) were modified and the other ones (12 items) were deleted; because they were redundant or ambiguous. The final version of the TABS consisted of 78 items. Concurrent validity was also assessed by using the Student Jenkins Activity Survey (SJAS) developed by (Jenkins, Zyzanski, \& Rosenman, 1979). The (SJAS) is a 21-item self-report questionnaire that yields a composite Type $A$ scale score in college undergraduates. To adjust SJA S to Omani environment ; it was trans- lated to Arabic by authors, then both original and Arabic versions were submitted to a panel of experts to assess content validity. TABS and SJAS were administered to a pilot sample of 20 students at the university. Correlation coefficient between the two scale scores was ( $r$ $=0.67$, significant at $p=0.0001$ ), which means that TABS is shown to have strong validity.

\section{Reliability}

Reliability of the TABS was estimated in two ways: test-retest reliability and internal consistency. To estimate test - retest reliability, a pilot study was conducted twice with an interval of 3 weeks on 20 students at the university. The correlation coefficient between the first time scores and the second time scores of conducting the pilot study was calculated, and it was found to be ( $r=0.79$, significant at $p<$ 0.01 ). Internal consistency was calculated by Cronbach Alpha for all items and dimensions. The total Cronbach Alpha coefficient was 0.87, while Cronbach Alpha coefficients for the dimensions (subscales) were as follows: 0.89 for urgency, irritability - impatience dimension, 0.85 for energy - ambition, competitiveness dimension, 0.87 for hostility- aggressiveness dimension and 0.88 for hostility- aggressiveness dimension. All told, these values indicate appreciable and stable reliabilities for the TABS scores.

\section{The Counseling program}

This program was designed based on Rational Emotive Behavioral Therapy (REBT) of Ellis, Cognitive Therapy (CT) of Beck, and research of Möller and Botha (1996). The purpose of it was to: a. Educate participants about the TA BP and its consequences, as well as how our perceptions, beliefs and rules of living result in and maintain these Type A behaviors, b. Assist participants in identifying and replacing their dysfunctional beliefs through cognitive restructuring, and c. Help them develop healthier behaviors through behavioral assignments and exercises. The program validity was assessed by a panel of professors in counseling and psychotherapy. It was modified according to their feedback. The counseling program entails 10 weekly group sessions of 1.5-2 hours each as follows:

\section{Sessions 1-2}

Session 1: A part from a brief discussion of the goals of treatment, the expectations of partici- 
pants, treatment adherence, and the collaborative nature of the treatment relationship, the first session is devoted to an interactive discussion of the TABP. The signs and symptoms of the TABP, as well as its consequences, particularly in terms of general well-being and interpersonal relationships, are presented by the group leader, while participants are encouraged to present and discuss concrete examples of their own Type A behaviors, so as to foster self-understanding and group cohesion. In particular, the typical concern of group members that a reduction in the TAPB may adversely affect job involvement and performance is discussed, and the leader shares the research evidence that Type A behavior is irrelevant to success. At the end of the session, participants are requested to read a handout on the TABP during the coming week and, in order to help increase self-awareness, to keep a diary of their Type A behaviors and to bring it to the next session.

Session 2: This session starts with feedback and a discussion of the previous week's homework. The focus is then shifted to the role of cognitions in facilitating and maintaining emotions and behaviors. It is presented in terms of the $A B C$ model, where $A$ refers to activating events (including thoughts and images), $B$ refers to beliefs, and $C$ to the emotional and behavioral consequences. It is stressed that Type A behaviors and emotions are not so much a result of environmental circumstances as the way in which these circumstances are perceived. The dysfunctional evaluative beliefs and the criteria for functional/ dysfunctional beliefs are discussed, and the $A B C$ model is demonstrated by means of recent examples of Type A behaviors provided by group members. In addition to dysfunctional beliefs, Type As are prone to certain cognitive errors. These include all-or-nothing thinking (the tendency to evaluate things in absolutistic or dichotomous categories, as either black or white, win or lose, success or failure); selective attention (directing the attention toward select aspects of environmental information, e.g., liabilities and failures); personalization (consistently exaggerating one's own importance, e.g., attributing one's own views to others, without questioning whether they have their own frames of reference); and attributions of causality (because Type As are inclined to attribute their success to effort and trying hard, when they fail they are inclined to believe that they did not try hard enough and to fault themselves for not trying harder). In addition to discussing dysfunctional beliefs, the group leader will point out these cognitive errors and examine them throughout treatment. Homework for the next week includes a) a behavioral exercise in which two Type $A$ behaviors are selected from the previous week's diary and replaced with Type B behaviors (e.g., walk/ eat slower; remain at the dinner table longer; relax while waiting in a line or driving in traffic), b) reading a handout on the ABC model, dysfunctional evaluative beliefs and the criteria for dysfunctional be liefs, and c) keeping a diary of Type A behaviors and emotions that includes the circumstances under which they occur, i.e., the activating events (A), the automatic thoughts (or beliefs) accompanying these events (B), and the emotional and behavioral consequences (C).

\section{Sessions 3-10}

Sessions 3 through 8 examine the dysfunctional thinking associated with specific subcomponents of the TABP, and provide other exercises for establishing al ternative Type $B$ behaviors. Sessions 9 and 10 deal with the consequences of Type A behavior on interpersonal relationships, and examine self-esteem as a core element in maintaining the TABP. The leader emphasizes that these components are not unrelated. For example, dealing with anger and hostility may uncover dysfunctional beliefs regarding interpersonal relationships, or competitive, hard-driving behavior may be related to a negative self-rating. These sessions also include other exercises and techniques, such as: progressive relaxation training.

\section{Procedures}

After constructing the scale (TABS) and finding its psychometric characteristics, it was administered to both classes (experimental and control groups) as a pretest. A counseling program was applied to the experimental group for 12 weeks. After finishing this program, the TABS was also administered to both groups as a posttest.

\section{Study design and statistical analysis}

This study is considered as a nonequivalent pretest - posttest control group design that is one of quasi-experimental designs. This design is nonequivalent; because the participants are not equivalent in the same age and study lev- 
el. M eans and standard deviations were calculated and analysis of covariance was utilized with group as a main effect and the pretest as the covariate.

\section{RESULTS}

Data collected from both groups were analyzed by SPSS version 21. Table 1 illustrates means and standard deviations of participants' scores on the TABS according to group and gender.

Table 1

M eans and standard deviations of participants' scores on the TABS

\begin{tabular}{lccccc}
\hline & \multirow{2}{c}{ on the TA BS } \\
\cline { 3 - 6 } & $\mathrm{N}$ & $\mathrm{M}$ & $\mathrm{SD}$ & $\mathrm{M}$ & $\mathrm{SD}$ \\
\hline Experimental & 12 & 291.58 & 46.58 & 181.42 & 17.83 \\
Control & 12 & 288.25 & 50.26 & 293.08 & 51.85 \\
Total & 24 & & & 237.25 & 68.50
\end{tabular}

Table 1 shows that there were noticeable differences between subjects' pretest and posttest means on the TABS in the experimental group; that is, total pretest mean was 291.58 , and total posttest mean was 181.42, but in the control group the difference was small. That is, total pretest mean was 288.25 , and total posttest mean was 293.08. The findings revealed that there were no significant difference, $F(1,21)$ $=24.877$, ( $p=0.069)$ between the experimental group and the control group in pretest. However, there was asignificant difference, $F(1,21)$ $=107.330$, $(p=0.0001$, effect size $=0.896$ ) between the experimental group and the control group in the reduction of Type A behavior in posttest (Table 2). These results mean that the experimental group whose individuals received the group counseling program outperformed the control group whose individuals didn't receive any treatment in the reduction of Type A behavior. This significant reduction was greatly in favor of the experimental group subjects whose posttest mean on the TABS was 181.42, while the control group subjects' posttest mean was 293.08 .

\section{DISCUSSION AND CONCLUSION}

There was a significant effect of group counseling program based on cognitive - behavioral therapy on the reduction of Type $A$ behavior. The treatment progress made in the Type A behavior for the experimental group subjects reflects the importance of group cognitive-behavioral therapy compared to other interventions or techniques in the treatment of this behavior. Related literature showed the role of this kind of therapy in modifying different disorders, such as: anxiety, social phobias, stress, depression and personality disorders; because cognitive-behavioral techniques and strategies mainly focus on client's cognitive structure which is considered as a crucial contributor of the development of mental disorders, so these therapeutic techniques help clients to reshape the cognitive structures (Cognitive restructuring) to play an important role in getting the client's beliefs more rational. Other therapeutic techniques may not be effective; because they only focus on the consequences of cognitive processes. These findings were consistent with the studies of: Sorensen (2006), Federal Information \& News Dispatch (2001), George, Prasadarao, Kumaraiah, \& Yavagal (1998), Möller and Botha (1996), Burell, Ohman, Sundin ,Strom, Ramund, Culhed and Thoresen (1994) and Bennett, Wallace, Carroll, and Smith (1991) which proved the effect of cognitive-behavioral techniques on modifying Type A behavior. It is concluded that a wellconstructed therapeutic program will strongly affect the treatment of Type $A$ behavior, which means that individuals with this pattern of behavior are capable of changing their irrational beliefs that may contribute to cause this behavior; because these programs teach them how to increase their awareness of belief system and abnormal behaviors related to it. The findings of this research supports that cognitive-behavioral treatment is more effective in treating Type A behaviors than are other types

Table 2

Analysis of covariance on the effect of group on the TA BS

\begin{tabular}{lrrrrrr}
\multicolumn{1}{c}{ Analysis of covariance on the effect of group on the TABS } \\
\hline Source & SS & DF & MS & F & P & Effect size \\
Corrected Model & 92750.029 & 2 & 46375.014 & 64.331 & $0.0001^{*}$ & 0.860 \\
Intercept & 2643.336 & 1 & 2643.336 & 3.667 & $0.0001^{*}$ & 0.149 \\
Pre & 17933.362 & 1 & 17933.362 & 24.877 & 0.0690 & 0.452 \\
Group & 77371.879 & 1 & 77371.879 & 107.330 & $0.0001^{*}$ \\
Error & 15138.471 & 21 & 720.880 & & 0.896 \\
Total & 1458790.000 & 24 & & & \\
Corrected Total & 107888.500 & 23 & & & \\
\hline
\end{tabular}

*. Significant at $\alpha<0.05$ 
of treatment; that is psychotherapeutic interventions, on the other hand, have proven less effective in modifying Type $A$ behavior than behavioral approaches; because these interventions do not focus on individual's cognitive structure or belief system. Cognitive - behavioral therapy includes diverse techniques contributed to reduce this kind of behavior. Future research should focus on replicating these findings or on comparing behavioral approaches to cognitive-behavioral approaches of treatment.

\section{REFEREN CES}

Beck, A., \& Emery, G. (1985). A nxiety disorders and phobias: A cognitive perspective. New York: Basic Books.

Beck, A. T., \& Weishaar M. E. (2008). Cognitive therapy. In R. J. Corsini \& D. Wedding (Eds.), Current psychotherapies (8th ed., pp. 263- 294). Belmont, CA: Brooks/ Cole.

Begley, T.M ., Lee, C. \& Czajka, J.M. (2000). The relationships of Type $A$ behavior and optimism with job performance and blood pressure. Journal of Business and Psychology. 15(2), 215-227.

Bennett P., Wallace L., Carroll, D., \& Smith, N. (1991) Treating Type A behaviors and mild hypertension in middle-aged men. Journal of psychosomatic research, 35(2-3), 209-223.

Bracke, P.E, \& Thoresen, C., E. (1996) Reducing Type $A$ behavior patterns: a structural group approach. In Allan, R, \& Scheidt, S. (Eds.) $\mathrm{H}$ eart and mind. The practice of cardial psychology. Washington, DC: American Psychological Association, pp. 255-290.

Burell, G., Öhman, A., Sundin, O., Strom, G., Ramund, B., Culhed, I. \& Thoresen . C. E. (1994). Modification of the Type A behavior pattern in post--myocardial infarction patients: a route to cardiac rehabilitation. International Journal of Behavioral M edicine, 1(1), 32.

Compare, A., Manzoni, G. M. and Molinari, E. (2006). Type A, type $D$, anger-prone behavior and risk of relapse in CHD patients. In E. Molinari, A. Compare and G. Parati (Eds.).Clinical Psychology and $\mathrm{H}$ eart D isease. Milan: Springer.
Corey, G. (2014). Theory and practice of counseling and psychotherapy. Belmont, CA: Brooks/ Cole.

Ellis, A. (1997). REBT and its application to group therapy. In J. Yankura and W. Dryden (eds.), Special applications of REBT: A therapist's casebook. New York: Springer Publishing Company, pp. 131-161.

Ellis, A. (2002). REBT and its application to group therapy. In W. Dryden and $\mathrm{M}$. Neenan (eds.), Rational-emotive behavior group therapy. Philadelphia: Whurr Publishers, pp. 30-54.

Federal Information \& News Dispatch. (2001, Feb 28). Type A behavior modification and research. Commerce Business Daily, Retrieved from:

http:/ / search.proquest.com/ docview/ 258803 422? accountid $=27575$.

Friedman, M. \& Rosenman, R.H. (1974). Type A Behavior and Your Heart. New York: Knopf.

George, I. M. Prasadarao, P. S., Kumaraiah, V, $\&$ Yavagal, S., T. (1998). Modification of the Type $A$ behavior pattern in coronary heart disease: A cognitive-behavioral intervention programme. $\mathrm{N}$ ational Institute of $M$ ental $\mathrm{H}$ ealth and Neuro Sciences (NIM H A N S) Journal, 16(1), 29-35.

Gerardi, M., Ressler, K., \& Rothbaum, B., O. (2009). Combined treatment of anxiety disorders. In Dan J. Steinand, E. Hollander \& B.O. Rothbaum (Eds.). Textbook of anxiety disorders. Washington: American Psychiatric Publishing, Inc., pp. 147-148.

Greenberg, J. (2008). Comprehensive stress management. Boston: McGraw-Hill.

Hemingway, M., M. (1999) Evidence based cardiology: psychosocial factors in the aetiology and prognosis of coronary heart disease Systematic Review of Prospective Cohort Studies. 318, 1460-1467.

Jenkins, C. D., Zyzanski, S. J., \& Rosenman, M. D. (1979). Jenkins Activity Survey. New York: Psychological Corporation.

Ledley, D. R., Marx, B. P., \& Heimberg, R. G. (2005). M aking cognitive-behavioral therapy work: Clinical processes for new practitioners. New York: Guilford Press. 
Lehrer, P. M., Woolfolk, R. L. \& Sime, W. S. (2007). Principles and practice of stress management. Los A ngeles: Guilford Press.

Moller, A. T., \& Botha, H.C. (1996) Effects of a group rational-emotive behavior therapy program on the Type A behavior pattern. Psychological Reports, 78, 947-961.

Quick, J. C., Quick, J. D., Nelson, D. L., \& Hurrell, J. (1997). Preventive stress management in organizations. Washington, DC: American Psychological Association.

Pedersen, S., and Denollet, J. (2003) Type D personality, cardiac events, and impaired quality of life: a review. European Journal of Cardiovascular Prevention and Rehabilitation, $10(40), 241-248$.

Rosenman R. H., Swan G. E., Carmelli, D. (1988) Definition, assessment, and evolution of the Type A behavior pattern. In Houston BK, Snyder CR (Eds.) Type A behavior pattern: research, theory and intervention. New York: Wiley, pp. 8-31.

Sorensen, T. J. (2006). Cognitive behavioral treatment of the Type A behavior pattern.
(Doctoral dissertation). Retrieved from Proquest Dissertations and Theses. (UMI 3209636).

Strike, P. C. and Steptoe, A. (2004) Psychosocial factors in the development of coronary artery disease. Progress in Cardiovascular Diseases, 46(4), 337-347.

Terjesen, M., D. \& Esposito, M., A. (2006). Rational-Emotive Behavior group therapy with children and adolescents .In A. Ellis and M E. Bernard (Eds.). Rational emotive behavioral approaches to childhood disorders: theory, practice and research. New York: Springer Publishing Company, pp. 385389.

Towbes, L. C. and Cohen, L. H.(1996) Chronic stress in the lives of college students: scale development and prospective prediction of distress. Journal of Youth and A dolescence, 25 ,199-217.

Williams, R. (2002). Hostility, psychosocial risk factors, changes in brain serotonergic function, and heart disease. In S. Stansfeld, and M. Marmot (Eds.). Stress. 